\title{
From Soil Pollution to "Cadmium Rice" to Public Health Impacts: An Interdisciplinary Analysis of Influencing Factors and Possible Responses
}

\author{
Jennifer HOLDAWAY ${ }^{1,2, *}$, WANG Wuyi ${ }^{2}$ \\ 1. School of Interdisciplinary Area Studies, University of Oxford, Oxford OX2 6LH, UK; \\ 2. Institute of Geographic Sciences and Natural Resources Research, Chinese Academy of Sciences, Beijing 100101, China
}

\begin{abstract}
This article discusses the causes of the contamination of rice with cadmium in China and considers what we know about the severity of the problem. It argues that it is misleading to extrapolate simply from levels of cadmium in soil to health risks, because the uptake of cadmium by crops and the health impacts of the metal are affected by multiple factors. These include not only background levels of cadmium and pollution from mining and industry, but also soil quality, climatic conditions and the type and variety of crops grown. Social and cultural factors, including dietary habits, other exposure sources, nutritional quality and general health status will also affect the intake of cadmium and the severity of health impacts. For these reasons we argue that interdisciplinary analysis is crucial to a better understanding of patterns of risk to health from cadmium pollution, and to the design of effective responsive measures.
\end{abstract}

Key words: soil pollution; food safety; cadmium; rice; environmental health; China

\section{Introduction}

Over the last few years, "cadmium rice" has been one of the most widely reported food safety problems in China. Although previous studies by the Ministry of Agriculture and academic researchers had found levels of cadmium above the national standard in samples collected in different parts of the country (Zhang et al., 2012), it was not until 2013 that the issue began to receive wider attention, with media reports that the Guangzhou Municipal Food and Drug Administration had found excessive levels of cadmium in samples of rice on sale in markets and restaurants in the city (Pang et al., 2013). This was followed in 2014 by the release of some statistics from the National Survey of Soil Pollution, which showed that $16 \%$ of soil samples contained excessive levels of heavy metals (Ministry of Environment \& Ministry of Land Resources (MEP \& MLR), 2014).

Public fear of contaminated rice is understandable, as the grain is a primary staple food in China and, like other heavy metals, cadmium has serious negative health effects. It damages kidney function and the bones, as well as contributing to various cancers ((U.S. Department of Health and Human Services, 2012). As cadmium's biological half-life is estimated to range from 6 to 38 years in the kidney and 4 to 19 years in the liver, cumulative exposure through food can lead to the slow build-up of the metal in the body of which people are not aware until it has become a serious threat to health (Tucker, 2011).

How big actually is the food safety risk from cadmium in China? How many people does it affect, and how seriously? This article explains why this question is harder to answer than it might seem. We discuss the factors that contribute to the risk of rice being contaminated with cadmium and that influence the level of exposure among different populations. We emphasize the importance of understanding the complex

Received: 2017-07-20 Accepted: 2017-11-07

Foundation: FORHEAD with funding from the Rockefeller Brothers Fund (RBF).

*Corresponding author: Jennifer Holdaway, E-mail: jennifer.holdaway@area.ox.ac.uk

Citation: Jennifer HOLDAWAY, WANG Wuyi. 2018. From Soil Pollution to "Cadmium Rice" to Public Health Impacts: An Interdisciplinary Analysis of Influencing Factors and Possible Responses. Journal of Resources and Ecology, 9(1): 10-21. 
relationship between levels of heavy metals in soil and crops, and levels of dietary intake and their health effects; and discuss what we know about each of these in the China context. We demonstrate how an interdisciplinary analysis can help in mapping out the landscape of risk, identifying potentially vulnerable populations and informing responses appropriate to different contexts.

\section{Factors affecting the risk of cadmium poisoning}

People can be exposed to cadmium through a number of exposure pathways, including the respiratory system and the skin as well as food and drinking water. Other heavy metals, including mercury and lead and arsenic, ${ }^{1}$ also have serious health effects, and can accumulate in food products or water. We focus here on cadmium because of its severe health effects and on rice because it is such an important staple food in China. China is the second largest rice producer in the world, with an output of 206.9 million tons in 2016 (Lu, 2016) and the seventh largest consumer, at an average per capita of about $86 \mathrm{~kg}$ per year in 2010 (Mohanty, 2013).

To understand the level of risk from cadmium exposure through rice for a given population we need to understand four things: 1) what determines the level of cadmium in soil;
2) what determines how much cadmium is absorbed by crops; 3) what determines how much of that cadmium is then taken in through food by various population groups; and 4) what determines the impact of the cadmium consumed on people's health. Table 1 shows the key environmental and social factors that interact to shape the distribution of risks from cadmium in food. As we will show, the implication of this complex structure of risk is that understanding how these factors play out in any given situation, and figuring out how best to reduce risk, requires knowledge from a number of natural, medical and social science disciplines, including amongst others soil chemistry, plant biochemistry, toxicology, epidemiology, nutritional science, agricultural science, rural development and economics, social psychology and anthropology, as well as public policy across multiple sectors.

Below, we discuss what we know about these factors on the national level and demonstrate the value of our interdisciplinary approach through analysis of a case study conducted by the Forum on Health, Environment and Development (FORHEAD) ${ }^{2}$. Building on earlier work by medical geographers from the Institute of Geographical Sciences and Natural Resources Research (IGSNRR) of the Chinese Academy of Sciences, since 2009 FORHEAD has supported

Table 1 From soil pollution to food safety: severity and distribution of health risks

\begin{tabular}{|c|c|c|c|c|c|c|}
\hline Drivers & Factor & $\begin{array}{l}\text { Concentration } \\
\text { in soil }\end{array}$ & $\begin{array}{l}\text { Uptake } \\
\text { by crops }\end{array}$ & $\begin{array}{l}\text { Human } \\
\text { Intake }\end{array}$ & $\begin{array}{l}\text { Local } \\
\text { Impacts }\end{array}$ & $\begin{array}{l}\text { Broader } \\
\text { impacts }\end{array}$ \\
\hline Naturally occurring high levels of cadmium & High background levels & • & & & & \\
\hline Mining or industry in vicinity upstream & Proximity of pollution source & - & & & & \\
\hline Scale and duration of production & Level of emissions & & & & & \\
\hline Presence or absence of pollution control & & & & & & \\
\hline Acid rain & Acidity of soil & - & . & & & \\
\hline Chemical fertilizer use & & & & & & \\
\hline Precipitation and groundwater situation & Moisture level of soil & • & • & & & \\
\hline $\begin{array}{l}\text { Past fertilizer and pesticide use } \\
\text { Over intensive cultivation }\end{array}$ & $\begin{array}{l}\text { Fertility of soil } \\
\text { (organic content) }\end{array}$ & • & • & & & \\
\hline Zinc, iron \& other elements in soil & Interaction effects & - & • & & & \\
\hline $\begin{array}{l}\text { Crop type } \\
\text { Rice cultivar }\end{array}$ & $\begin{array}{l}\text { Accumulation } \\
\text { propensity of crops }\end{array}$ & & • & & & \\
\hline $\begin{array}{l}\text { Regional diets } \\
\text { Alternative food sources }\end{array}$ & Intake level & & & • & • & \\
\hline $\begin{array}{l}\text { Nutritional balance } \\
\text { Age, sex and genetic factors }\end{array}$ & Health status & . & . & - & • & \\
\hline $\begin{array}{l}\text { Surplus production } \\
\text { Awareness of risk }\end{array}$ & $\begin{array}{l}\text { Sale of contaminated } \\
\text { rice on market }\end{array}$ & & & & • & . \\
\hline Regulation at harvest and sale & & & & & & \\
\hline
\end{tabular}

\footnotetext{
${ }^{1}$ Arsenic is not a heavy metal but is usually included in soil and water testing for heavy metals because of its serious health effects and propensity to affect health through these exposure pathways.

${ }^{2}$ For more information about FORHEAD see www.forhead.org
} 
a series of inter-linked research projects by natural, medical and social scientists from a range of disciplines to explore the environment, health and development dimensions of heavy metal mining in a county in Southwest Hunan (Fenghuang). The case, in which relatively small-scale mining co-exists with agriculture, represents a situation which is quite common in China, and illustrates many of the challenges involved in understanding and reducing the risks of heavy metal pollution to health.

This article presents an integrated analysis of information from many disciplines. This would not have been possible without the empirical research and discussions on these issues that have taken place within the FORHEAD network over many years. In particular, readers are urged to follow up on the references for additional information and perspectives regarding the Fenghuang project.

\section{Contamination: from the soil to the crop}

\subsection{Background levels and anthropogenic sources}

First of all, it is important to note that the presence of heavy metals in soil is not only the result of pollution. Cadmium and other heavy metals are a part of the chemical composition of the earth's crust and they are present at different levels in different parts of the world. In areas where they are mined, heavy metals are usually present at significant levels in all the soil in the area. This naturally occurring level of a certain metal in the soil is called the "background level." In China, heavy metal deposits form a broad belt that runs from the northeast through to the southwest (Zhang et al., 2012).

Levels of heavy metals in soil can be increased by a variety of human activities. For cadmium these include mining and metal smelting: cadmium is a side product of lead and zinc mining. Cadmium is also used in the battery, electro-plating and other industries. Other sources of cadmium pollution include the production of iron and steel; fossil fuel combustion; and waste incineration. Sewage sludge, animal manure and phosphate fertilizers can also contain cadmium (Alloway and Steinne, 1999).

Mining has naturally been concentrated in areas with large mineral deposits. Metal processing industries have followed the same pattern but have also clustered around major industrial centres in Northeast China, Shanghai and Guangdong, causing pollution in these areas (Zhang et al., 2012). In 2007, emissions from lead/zinc mining and smelting in China were 1.62 and 3.32 million tons, respectively. Ore-dressing procedures were the major contributors (almost $50 \%$ ) to total emissions, and lead and cadmium were the prominent pollutants (Zhang, 2011).

Heavy metals produced by airborne emissions can settle on crops, leaving residues, but here we are mostly concerned with contamination that takes place when crops absorb heavy metals from the soil. The 2014 Public Report on National Situation regarding Soil Pollution, states that $11.2 \%$, $2.3 \%, 1.5 \%$ and $1.1 \%$ of soil in China suffers from very light, light, medium and heavy pollution, with an overall $16.1 \%$ over national standards and $33.4 \%$ in mining areas. The figures given for farmland were slightly higher, with a total of $19.4 \%$ over the safe standard and $13.7 \%, 2.8 \%$, $1.8 \%$ and $1.1 \%$ with very light, light, medium and heavy pollution. The report states that $7 \%$ of samples were found to contain excessive levels of cadmium of which $5.2 \%$, $0.8 \%, 0.5 \%$ and $0.5 \%$ had very light, light, medium and serious levels of pollution; and that concentrations are highest in mining and industrial areas (MEP \& MLR 2014). These figures are based on the standards for safe levels of heavy metals in soil (GB 15618-1995) adopted in 1995.

Another report, released in June 2015 by the Ministry of Land Resources presented a slightly more optimistic picture, stating that, according to the same standard above, $91.8 \%$ of farmland in China was free of heavy metal pollution and only $8.2 \%$ polluted (MLR 2015). Given that the MLR and MEP collaborated on the survey, it is not clear why the statistics in the two reports differ and this discrepancy is confusing. However, several points are worth noting. First, the major difference concerns light and very light pollution; the statistics for medium and heavy pollution in both reports are similar $(2.9 \%$ and $2.5 \%$, respectively). Second, the more detailed information about cross-province variation in the 2015 report confirms the distribution of pollution that would be expected, with the percentage of land said to be free of pollution ranging from a high of $99.1 \%$ in the Beijing-Tianjin-Hebei-Shanxi region to a low of $82.1 \%$ in the Hunan-Hubei-Jiangxi-Anhui region (MLR 2015). Lastly, the report also stresses the interaction between high background levels of heavy metals and human activity, attributing more than $80 \%$ of excess levels of heavy metals in samples from Hunan and the Southwest to underlying earth chemistry (MLR 2015).

Inter-ministry discrepancies aside, what should we make of these figures? Many media reports imply that it is possible to extrapolate directly from soil pollution statistics to estimate the risk from heavy metals through food, but this is misleading. First, we should be cautious in interpreting the implications for food safety because the sampling frames were large: $1 \mathrm{~km}^{2}$, or a scale of 1:250,000. Smaller scale sampling was conducted in some places but the results were not reported. Because pollution is unlikely to be evenly or randomly distributed, it is quite possible that the survey findings under-estimate the extent of pollution in some places and over-estimate it in others, but not in a way that results in an accurate "average" result. Much more detailed surveys with smaller sampling frames, which are currently being conducted, will be needed to give a more accurate estimate of the actual amount of land that is polluted. Because it is extremely expensive and time consuming to conduct finer grained testing (the MLR survey took 15 years and 2 billion RMB), the focus will be on areas known to be at high risk of pollution. Various geostastical models are 
also being developed to estimate the distribution of pollution of varying degrees (for example, Xie et al., 2015).

The other reason to be cautious in interpreting the implications of these soil pollution statistics for food safety is that although high concentrations of heavy metals, whether naturally occurring or due to pollution, create the possibility of crops becoming contaminated, certain other conditions must pertain for this to occur and affect the uptake of heavy metals by food crops. These conditions include the $\mathrm{pH}$ and characteristics of the soil, moisture levels, temperature, and the type and varietal of crops planted. We discuss each of these in the sections that follow.

\subsection{The mobility of cadmium: soil quality, crop type and bioavailability}

Heavy metals have particular chemical properties that affect their behavior in the soil and their interaction with plants. Of particular importance is the fact that different heavy metals become "bioavailable," (able to be absorbed by crops), under different environmental conditions. Soil $\mathrm{pH}$ is usually regarded as the most significant variable, with decreasing soil $\mathrm{pH}$ increasing cadmium uptake by plants (Chaney, 2012; McBride, 2002) ${ }^{3}$. Other factors include the organic content of the soil (high organic content tends to reduce absorption of cadmium by plants), its moisture level, and the temperature. The last two factors mean that even if the same crop is grown in the same field at a different time of year (for example early and late rice), it may absorb different levels of heavy metals. Because weather conditions can be variable, these factors can be quite difficult to predict or manage. Generally, however, due to its chemical properties, cadmium is the most mobile of heavy metals (Zhang, 2011).

Overall, China's soil is in poor condition, with over half of arable land short of microelements, phosphorus and potassium, and low organic content (CCICED, 2010). Due to long term soil development, most soils in southern China are acidic. This means that although background levels of cadmium are lower than in Japan, heavy metal uptake rates are often higher and crops can be unsafe even when levels of heavy metals in the soil are within permissible limits (CCICED, 2010). The 2015 MLR report indicates that the problems of low organic content and acidity have worsened in many parts of China since the last survey in the 1980s and that protection of soil must be a priority to reduce the bioavailability of heavy metals as well as to maintain the nutritional content of food (MLR 2015)

The type of crop that is grown is another crucial factor. Some types of food crop have much higher propensities to absorb cadmium than others, including rice and durum wheat, sunflowers, flax, peanuts, potatoes, soybeans and many kinds of leafy greens such as cabbage and spinach.
Other plants may accumulate cadmium, but not in parts that are usually eaten (Grant et al., 1999). However, even within the same crop species different cultivars can have very different propensities to absorb cadmium (Grant et al., 2008; Yu et al., 2006), and the same cultivars also respond differently to different levels of pollution (Yu et al., 2006).

These differences are very important in the China context. In general, for example, Japonica rice, which is predominantly grown in North China, has a lower propensity to absorb cadmium than Indica rice, which is mostly grown in the south. But even within these two broad types there are differences. Field studies of rice in China have found that, depending on soil conditions and levels of pollution, differences in cultivar type can make the difference between whether or not cadmium concentrations are within safe levels (Chen and Wang 2018; Shi et al., 2009; Yu et al., 2006) Some of the high-yield varietals that have been promoted in China in order to increase harvests have a particularly high propensity to absorb cadmium (Shi et al., 2009).

\subsection{Agricultural practices and food safety}

The two sections above make it clear that food safety is not just a question of the level of heavy metals in the soil; it is also related to agricultural practices, which, as we show in table 1, add another layer of factors that influence the risk of food crops becoming contaminated. Most specifically, practices that degrade the soil or increase its acidity - including over intensive farming and the use of chemical fertilizers will generally increase the mobility of cadmium, while practices that improve soil quality and raise its $\mathrm{pH}$ will reduce it (Chaney, 2012). The choice of rice cultivar is also very important, because some strains will be more likely than others to accumulate whatever cadmium is available (Shi et al., 2009; Grant et al., 2008; Yu et al., 2006). In combination, these factors mean that it is possible that rice will have excessive levels of cadmium even when soil is within the "safe" standard. At the same time, it can sometimes be possible to grow safe food even in soil that exceeds the standard.

Mapping of the distribution and interaction of these influencing factors across different parts of China indicates that the risk is much higher in some places than others. and concentrated in the south of the country where the underlying risk from high background levels of heavy metals is compounded by the coexistence in many places of metal mining and processing with rice production; acidic soil and a preference for Indica rice, which has a higher propensity to accumulate cadmium. While this may initially seem a depressing picture, a detailed understanding of these influencing factors also points to ways in which the chain through which cadmium passes from the soil to food crops can be broken.

\footnotetext{
${ }^{3}$ Soil $\mathrm{pH}$ is the numeric expression of acidity, with decreasing $\mathrm{pH}$ indicating greater acidity.
} 
The situation of the mining village in Fenghuang where the FORHEAD team has worked illustrates these complexities. The field site is situated in a mountainous area of Fenghuang County, in western Hunan. While the county town has become quite affluent through tourism, this remote area is still poor. It does, however, have rich mineral deposits, in particular lead and zinc. ${ }^{4}$ Since the late 1950s, these have been exploited, first by a sizeable state-owned mine, which was later privatized, and also by the local farmers, who have dug multiple small pits in their contracted land. This has resulted in piles of tailings and waste water ponds of different sizes being scattered throughout the area. As cadmium is a side product of lead and zinc mining, this, along with lead, mercury and arsenic, is a potential risk to human health ( $\mathrm{Li}$ et al., 2013a, 2012; Zhang, 2011). Although other heavy metals and other exposure pathways are also important ( $\mathrm{Li}$ et al., 2013b; Zhang, 2011; Sun et al., 2010), here we focus primarily on the problem of cadmium in rice.

Medical geographers from the Institute of Geographical Sciences and Natural Resources Research (IGSNRR) of the Chinese Academy of Sciences have conducted research in the area since the early 2000s, first testing the soil and surface water for heavy metals, and later testing food products and drinking water in order to understand the most important pathways of human exposure. They also tested the hair and blood of local residents (Li et al., 2012; Zhang, 2011).

Initial tests found that, as would be expected, background levels of heavy metals throughout the area were high, even in the control area where mining does not take place. There is therefore an underlying general risk that needs to be considered throughout the region, because under the wrong conditions of soil acidity and climate factors, these metals may become bioavailable and contaminate crops. Levels of cadmium in the mining area were much higher than in the background area (Li et al., 2012; Zhang, 2011). However, the situation is quite complicated. Different rounds of testing between 2005 and 2013 found that levels of different heavy metals in the soil varied considerably over time and also within the area, in ways that were not entirely predictable, although concentrations were generally higher in areas downstream from extractive activity (Zhang, 2011).

This case illustrates that surveys with a large sampling frame are of little use in understanding risks in such a local context. Within a $1 \mathrm{~km}^{2}$ area there can be considerable diversity in levels of heavy metals in soil. Furthermore, the situation is constantly changing. Later tests showed falling levels of most heavy metals, probably because the intensity of mining has declined due to a combination of stricter environmental protection and the falling price of minerals (Zhang, 2011). This shows the importance of continuing to address the problem of contaminated rice at its source, by preventing and controlling pollution from mining.

In 2009, the IGSNRR team tested food crops and drinking water for four heavy metals and arsenic and performed an exposure pathway analysis based on actual intake levels. Rice was found to be the dominant source of exposure to heavy metals, accounting for $90 \%$ of villagers' exposure, and cadmium to be the most serious problem (Zhang, 2011: 70) This is not surprising given the high bioavailability of cadmium and the fact that Indica rice varietals are grown in the area.

Further testing of soil and crops in 2013-15 by Chen Nengchang found that levels of cadmium were lower than before, probably because mining activity had decreased. ${ }^{5}$ Levels of cadmium in rice were also lower than might have been expected based on the soil samples. This is probably because of the characteristics of the soil and the fact that the soil is not highly acidic. However, the tests also showed that levels of cadmium in rice planted in different fields within the area varied and were not always easily related to the levels in the soil. In one case, the team was surprised to find that rice planted in a field directly below a mine tailing pond, which was heavily contaminated with heavy metals, was in fact within safe levels for cadmium. We later found that the farmer had been applying alkaline fertilizer. This illustrates the importance of understanding the role of agricultural practices in reducing the potential for food crops to become contaminated.

What are the practical implications of this analysis? We can see that the field site falls in the broad region of concern about cadmium contamination of rice, being an area with high background levels of heavy metals compounded by pollution from mining activity. In terms of agricultural practices, Indica rice is the primary crop and staple food, raising the barometer of risk. On the positive side, soil $\mathrm{pH}$ and composition are relatively good. Testing of crops shows that the majority of farmers are now not at high risk, but at the same time, rice produced in a certain number of fields is unsafe and the percentage could easily increase if pollution from mining increases and/or soil quality deteriorates. Furthermore, because some people have already been exposed to heavy metals for a long period of time, it is important to keep future intake levels as low as possible.

\subsection{Economic, cultural and psychological factors}

In many cases, then, it is interactions between the natural environment and human activities, including mining and agriculture, that shape levels of risk from heavy metals. In addition to the relevant natural sciences, it is therefore also important to understand the economic, political and social contexts in which these processes are taking place. For example, although both factors are present, the situation in Fenghuang is not a straightforward story of an irreponsible

\footnotetext{
${ }^{4}$ Mercury is also mined in a nearby area, and contributes to pollution, but for the sake of clarity we limit ourselves to the FORHEAD field site here.

${ }^{5}$ It should be noted that the two sets of samples were not directly comparable. See the cited publications for more details.
} 
mining enterprise and the failure of environmental regulation, but one in which local villagers have themselves participated to some extent. Readers may be wondering why, given the risk to their own health, villagers in Fenghuang would engage in mining or why, given that rice is the major source of exposure to cadmium, they continue to grow and eat it. The FORHEAD team has included social scientists, who have explored these factors as well as developing a broader picture of the history of the area and villagers' understandings of the relationship between mining, environment and health. More detailed accounts of their findings can be found in Lu and Lora-Wainwright (2014) and Zheng et al., (2015), but we summarize the relevant points briefly here.

The county-owned state mine opened in 1958 and considerably expanded its operations in the 1970s, a process typical of the promotion of rural industrial development in China at the time. The mine commandeered a substantial amount of agricultural land, but it brought workers in from outside, and so generated little employment for the local villagers, whose main complaint during this period was that they were not permitted to mine themselves. Although the mine caused serious pollution, at that time environmental regulation was more or less non-existent in rural areas ( $\mathrm{Lu}$ and Lora-Wainwright, 2014).

In the 1980s economic reforms dismantled collective agriculture and fields were contracted out to farmers; mineral prices also sky-rocketed. Many villagers, alone or in collaboration, began to dig pits in their fields ( $\mathrm{Lu}$ and Lora Wainwright, 2014; Zhang, 2011). Although some lost their investment when they failed to find adequate seams of minerals, mining and related sideline activities significantly raised the incomes of many households. Ran Shenghong of IGSNRR, who conducted this part of the analysis, found that on average, at the peak of activity, mining brought six times the income of agriculture and comprised more than $50 \%$ of the income of many households. Because it does not require leaving home and family, mining was also preferred to migration, which was the other main non-agricultural livelihood option (Lu and Lora Wainwright, 2014).

After 2007, the government began to more strongly enforce environmental protection policies, and many small mines in the village were closed. This coincided with falling prices for minerals on international markets, which led to a drop in production in the larger mining enterprises in the area. While most small mines have not re-opened, in 2017, several large mines were still operating in the area and one had received approval to increase production. This again reflects government policies, which encourage the scaling up of production in order both to improve efficiency and facilitate environmental monitoring. However, supervision of these mines has been inadequate, and they continue to cause pollution downstream. Over the period of the FORHEAD research there were also a number of incidents where the walls of tailing ponds collapsed and waste water flooded fields.

There is clearly an urgent need for stronger environmental monitoring of the large mines in the area. Meanwhile, from the point of view of the local environment and public health, the ban on small-scale mining is clearly necessary, but the area is poor, and a major challenge is how local farmers can increase their incomes in other ways. This is not easy in an area which is too remote to attract much tourism and in which mining has already spoilt the natural scenery. Regardless of the actual risk, outsiders are also wary of buying agricultural products grown there. A recent government- sponsored approach to poverty-alleviation has been to encourage villagers to move to local towns, but so far it seems that few villagers are willing to do so because the subsidies being offered are low and the opportunities for work limited.

Although they have been unevenly spread, the economic returns to mining are obviously a strong motivation for villagers to mine, even when they can see the damage that it does to the local environment: in 2012 , only $28 \%$ of villagers said that they were somewhat $(26 \%)$ or very $(2 \%)$ opposed to mining. Later analysis by Zheng and colleagues (2015) also showed that villagers' perceptions of the health risks from mining were correlated with their level of economic benefit. The risk therefore remains that villagers will return to mining if mineral prices rise and enforcement slacks off.

Although some of them have been vocal in protesting against pollution from the large mining operations (Lora Wainwright 2017), the villagers were mostly not aware until recently of the risk to health from contaminated rice. Nor, indeed, were most people in China, because it is not a risk that is immediately evident. Social psychological research has found, and this makes intuitive sense, that people are generally more likely to emphasize risks that are visible and acute over those that are less obvious and longer term in their effects. They also worry more about risks that are seen as being out of their control than risks that are related to their own behaviour (Slovic, 1987).

These factors are evident in this case. Lu, Lora Wainwright and Zheng found that villagers were more concerned about the risk to their health from water than from food (Lora Wainwright, 2017). At a later workshop with villagers that focused on food safety, some participants also expressed greater concern about lead than about cadmium, despite the media focus on "cadmium rice." This is also understandable. Heavy metal pollution of both soil and water is invisible, but because mining radically reduced the water supply and rendered surface water dark and odorous, villagers were naturally very concerned about this. Given that they were mining lead and zinc, these were the metals they were worried about, rather than cadmium, which is a side product of which they could not be aware. They were also more generally concerned to secure an adequate supply of drinking water (Lora Wainwright, 2017). The problem of 
food safety was less evident, since, although affected by the falling water table, rice production remained possible, and falling yields rather than safety were of greater concern to villagers. Earlier research has also found that farmers tend to have greater confidence in the safety of crops they grow themselves than in food bought on the market, even when they are living in areas with significant pollution, probably because they feel more in control (for example, Lora Wainwright et al., 2012).

At the same time, practical considerations may also come into play. Piped water was a demand that had some hope of being met, given that the government has a program to improve the rural drinking water supply (gaishui) and villagers had been promised, but never effectively provided with, piped water (Lora Wainwright, 2017). This demand could also potentially be met without affecting villagers' short term economic interest in continuing to mine.

\section{Markets, diets and intake levels: from crops to people}

Setting aside the complexities of how it gets there, how many people in China are consuming excessive levels of cadmium through rice? Two questions are relevant here: the percentage of rice that contains "excessive" cadmium; and the actual cadmium intake levels of specific populations.

China's standard for permissible levels of cadmium in rice is $0.2 \mathrm{mg} \mathrm{kg}^{-1}$. This is stricter than the standard used in some other countries of $0.4 \mathrm{mg} \mathrm{kg}^{-1}$ because it is related to the second standard: the maximum amount of cadmium it is considered tolerable for a person to consume on a weekly or monthly basis. For this, China has adopted the World Health Organization's provisional tolerable monthly intake for cadmium of $25 \mu \mathrm{g}$ per kilogram of body weight (i.e. 50-58 $\mu \mathrm{g}$ of cadmium per day for an average $60 \mathrm{~kg}$ woman or 70 $\mathrm{kg}$ man). The Chinese Centre for Disease Control and Prevention has set the standard for rice at a strict level because the grain's role as a staple food means that Chinese are likely to reach the daily tolerable level more quickly than people in countries where rice is consumed in smaller amounts (Wu and Li, 2015; Li, 2017).

\subsection{Levels of cadmium in rice}

Although intake levels are a key measure of the risk to health from cadmium, it is important to understand the underlying risk represented by the percentage of rice that is above the standard for cadmium. Unfortunately, we do not know precisely what this is, for two reasons. The first is that some rice never reaches the market, but is grown and consumed locally by self-sufficient farmers. What percentage this is of total rice consumption is unknown. The other reason is that, although all rice sold commercially is inspected and graded in terms of the number of whole kernels and other physical attributes, at no point is all rice sent to market subject to testing for heavy metals. Although the govern- ment has released data based on testing of rice in national storage facilities for arsenic (Li, 2018), it has not released similar data for cadmium, presumably because it is regarded as too sensitive. Data from the National Contamination Monitoring Network is not public either (Li, 2018).

The information we have on levels of cadmium in rice therefore currently comes mostly a limited number of studies conducted by academics or NGOs that have tested crops at the time of harvesting or rice that is on sale in various retail outlets. Most of these are small studies and while the findings may be accurate for the location, it is hard to generalize from them. For example, testing of rice crops is often conducted either in areas close to mines or factories or to assess the potential for "green" agriculture in relatively clean environments, so the findings probably reflect the extremes of the distribution rather than the average situation (see FORHEAD, 2014 for a summary).

Municipal governments sometimes also release information from food safety investigations, but this can also be hard to interpret. For example, in 2013 the Guangzhou Municipal Food and Drug Administration (GMFDA) and the Provincial Food Safety Office reported that $44.4 \%$ of rice and rice product samples ( 8 out of 18) from restaurant kitchens in the city had unsafe levels of cadmium. However, the GMFDA later reported that larger tests of 762 samples of rice from inventories at each of Guangdong's 618 rice production and processing companies found that only 31 (or about 5\%) were over the national standard for cadmium (Pang et al., 2013). This is a very substantial difference. (A recent study by Chen Nengchang, found that just over $25 \%$ of 125 samples collected from different retail outlets in the city were over the national standard for cadmium (Chen 2018).)

What are we to make of this? All these studies tell us something about the situation in various places but there is currently no good, publicly available data that captures the overall situation regarding levels of cadmium in rice. However, because there is great variation across and within different provinces, debating national averages is probably less important than identifying patterns of pollution and food safety risks and targeting resources accordingly.

\subsection{Dietary intake levels}

Two other sources help to fill out the picture in terms of human cadmium intake through rice which, because it depends on the amount and type of rice consumed, is another crucial factor in assessing health risks.

The China Statistical Bureau collects data on the amount of food of various types that is consumed at home by rural and urban people of different income levels. This survey excludes food consumed outside the home and so underestimates total consumption for all population groups (especially urbanites who eat out a lot and migrants who may have limited access to cooking facilities), but it does provide 
important information about regional and rural-urban variations in the consumption of rice. Analysis of this data shows that urban people consume less than half as much rice as rural people, with the annual average fairly stable from 2000-2010 (dropping from $46 \mathrm{~kg}$ to $40 \mathrm{~kg}$ ). Rural consumption levels fell quite dramatically over this period, from $123 \mathrm{~kg}$ to $102 \mathrm{~kg}$, reflecting the convergence of dietary patterns (Zhou et al., 2012).

Rice consumption is predictably higher in south China. With the exception of Heilongjiang, which is a major rice producing province, no other northern province has an average annual consumption of more than $100 \mathrm{~kg}$ per annum. Hunan has the highest average consumption level of over $200 \mathrm{~kg}$ a year in 2010 (Zhou et al., 2012). We can see from this that food safety problems related to rice are likely to be concentrated among rural people in south China. Given their lower consumption levels, urbanites and northern Chinese are unlikely to have dangerously high levels of cadmium intake through rice.

The China Total Diet Study (TDS) has been conducted five times since 1990, and it provides the best information available about actual intake levels of chemical contaminants in food. This is because the study collects and analyses food that is bought and cooked according to the culinary practices of different provinces and calculates daily consumption based on actual diets (for more about the TDS and its methodology see $\mathrm{Li}, 2018$, and $\mathrm{Wu}$ and $\mathrm{Li}, 2015$ ). It therefore makes it possible to assess people's intake of toxic substances from all sources as well as from individual food groups.

Results from the five TDS show that cadmium intake has shown a steady increase since the first study in 1990. Results from the most recent study showed that $19-33 \%$ of individuals of all age groups were consuming higher levels of cadmium from all sources than the provisional tolerable monthly intake (PTMI) and that this percentage is $30 \%$ for younger age groups (Wu and $\mathrm{Li}, 2015$; $\mathrm{Li} 2018$ ). In the $4^{\text {th }}$ TDS, levels of cadmium detected in cereals varied widely across provinces, from a low of $0.38 \mu \mathrm{g} \mathrm{kg}^{-1}$ in Hebei Province to a high of $67.60 \mu \mathrm{g} \mathrm{kg}^{-1}$ in Sichuan, reflecting the greater underlying risks in southern provinces due to the factors discussed above and dominant role of rice in the diet.

However, the TDS methodology also has limitations. The sample is based on dietary variation rather than the distribution of heavy metal pollution, and since it includes a limited number of provinces and only three sites for most provinces, it is not entirely clear the extent to which the findings represent the national or even the provincial situation. The study sample also specifically excluded areas known to be highly polluted or pristine in environmental terms. However, it does confirm that cadmium from dietary sources is a serious problem in southern China and is rightly a priority focus of food safety measures. In future, it is to be hoped that TDS sampling will be more closely linked to environmental and dietary risk factors for particular food safety risks.

The above trends are borne out by the Fenghuang case. Situated in Hunan province, where per capita rice consumption is highest, and being a poor rural area, it is not surprising that the major exposure pathway for cadmium intake was rice. Given this, in addition to advising farmers to protect the quality of soil by reducing chemical fertilizer use and switch to low-absorbing Japonica rice varietals, the FORHEAD team also recommended that villagers diversify their cereal intake and supplement their consumption of local rice with other staple foods such as wheat, as well as tubers which can be grown locally.

Of course, making such adjustments will also have economic and social dimensions. Diet is not only about nutrition but also about culture, and the substitution of food products may not come easily. However, while there was some concern in the team that villagers in Fenghuang might be unwilling to substitute Indica rice for Japonica due to the different texture and general preference for Indica in south China, the local CDC has reported that this does not seem to be the case. However, providing effective nutritional and agricultural guidance appropriate to local populations in different circumstances is a challenging task and there are currently no institutional mechanisms for doing this. When it comes to the diversification of staple foods, a harder constraint is that very poor rural people may not be able to afford to purchase grain, and subsidies may be needed to make this possible in areas where subsistence farmers are at risk.

At the same time, the discovery of cadmium tainted rice on sale in markets and restaurants, and the high levels of cadmium intake from rice across south China show that a considerable amount of contaminated rice must also be reaching the market. In addition to routine testing of rice, it will be important to identify new sources of safe staple foods for populations that are found to be at risk. In provinces like Hunan where many farmers are dependent on rice production, this also brings us back to the question of the alternative livelihoods available to rural people.

\section{From intake to disease: demography, nutrition and health status}

Maximum intake levels for heavy metals are designed to protect health under typical circumstances, but other factors come into play in determining the actual health impacts of cadmium intake through food. One is whether people are also exposed to the same substance through other channels. For example, tobacco smoking is a significant source of cadmium exposure because tobacco leaves naturally accumulate high levels of the metal (Elinder et al., 1983). Generally poor nutritional status has also been found to be associated with more serious health effects of cadmium and because the metal affects the bones, post-menopausal women 
who are prone to osteoporosis are at higher risk of cadmium related bone disease (Umemura, 2000).

Intake of other elements will also affect the way in which cadmium is metabolised within the body; for example, deficiencies of zinc, iron, calcium and dietary protein increase the toxicity of cadmium and the fact that these vary may partly explain why individuals with the same levels of dietary intake do not always have the same health effects (Chaney et al., 1999). How food is processed is relevant here, because it affects the presence of other chemicals that may inhibit or promote cadmium absorption. Polishing rice reduces its iron, zinc and calcium content and research has found that rats fed polished rice diets absorbed 10 times more cadmium than rats fed unpolished rice with adequate levels of iron, zinc and calcium (Reeves and Chaney, 2008). Meanwhile, a range of other foods have been shown to have protective effects against cadmium toxicity (Zhai et al., 2015).

Therefore, while it is of course important to reduce levels of cadmium in rice, in terms of short term measures to reduce health risks, these factors also point to priority populations for health monitoring and also to possible nutritional and public education interventions.

Again the Fenghuang case illustrates these complexities. The FORHEAD team has been able to conduct only limited testing of levels of heavy metals in villagers, hair and blood. Tests conducted in 2009 found that levels of cadmium, lead and mercury, as well as arsenic, were higher in the hair of villagers living in the mining area than those living in the control area (Li et al., 2012). Other biomarkers showed the impact of complex exposure to heavy metals on kidney function ( $\mathrm{Li}$ et al., 2013a). However, these biomarkers varied considerably within the sample, with some far above safe levels and others much lower (Li et al., 2013a, 2012; Zhang, 2011). Impacts of various metals also varied by age and by gender. It was surprising, given that men often also smoke and generally have higher occupational exposure, that women were found to be more affected by heavy metals than men, suggesting that their overall nutritional and health status may be poorer. This has implications for policy, implying that women should be a priority for health tests and interventions to protect health, including advice about nutrition. This was therefore also a focus of the FORHEAD public communication workshop.

\section{The geographic and demographic distribution of risk}

The above discussion has shown that, given the complexity of health impacts, the lack of good data and the way in which markets redistribute risks, it is currently impossible to make a full analysis of which populations are most exposed to cadmium through food. The information available from surveys of soil pollution, from testing of rice, and from studies of human intake levels is not entirely consistent, and insufficiently complete to conclude which is most accurate.
However, it seems that severe risks are probably fairly localized to people who live in the vicinity of mines and industries and/or in areas where soil quality has deteriorated, making cadmium more bioavailable; who eat a diet dominated by high accumulating rice cultivars over a long period; and who have poor nutritional status. In analysing the factors that contribute to cadmium-related illness, Chaney (2012) concluded, "the science is clear that diet-induced cadmium disease is very unusual except for rice subsistence farmers over 50 years old," and it seems that this is probably also true in China. However, in China this is still potentially a large number of people, concentrated in certain parts of the country.

Other populations are probably exposed to much lower levels of risk, partly because the majority of rice seems to be within safe levels, but also because the Chinese standard is set to protect people who eat large quantities of rice from the same source. This phenomenon is rarer as diets and supply chains are increasingly diverse. Urban diets in particular have diversified considerably in recent years, with the amount of rice consumed falling in relation to other food products (Zhou et al., 2012).

At the same time, limited testing of rice in retail outlets and the TDS data show that some contaminated rice is reaching the market; that a substantial number of people are exceeding permitted daily intake levels for cadmium; and that the problem is much more severe in south China than in the north. The relationship of intake levels of cadmium to income is not clear. Although some subsistence farmers are clearly at high risk, it is not necessarily the poorest regions or people that are the most vulnerable, as some very poor areas have no industrial pollution and relatively fertile soil, while others are heavily contaminated by mining or industrial pollution and have soil that may or may not also be seriously degraded from years of intensive agriculture, making cadmium more mobile and easily absorbed by crops. At the same time, rich areas may have a history of industry that has left serious legacy pollution. The types of crops that are planted and dietary habits, as well as how much food is home-grown or bought and migration flows, will also produce patterns of risk that cut across income levels (FORHEAD, 2014).

The complicated relationship between safety, nutritional quality and price is also clear from the analysis of Chen Nengchang (2018), who tested rice on sale at different prices in Guangzhou and found that while the most expensive rice generally contained much lower levels of cadmium, there was great variety in both levels of heavy metals and in nutrients in rice at lower price points. However, inequality is an issue not only in terms of the relationship between price and safety, but also in terms of the health status of different populations. Populations whose overall nutritional and health status is poor are more likely to suffer the health effects of cadmium exposure at the same level of intake and 
should be a priority for health monitoring and interventions to reduce risk.

Therefore, while we cannot make definitive analysis of patterns of risk, we can point to the factors that determine them, and which need to be monitored in any given setting to guide interventions and preventive measures. Table 1 above can serve as a rough guide for this process as well as for identifying the disciplinary expertise that is likely to be needed to understand the landscape of risk in different contexts.

\section{Conclusion: implications for policy and intervention measures}

The preceding analysis has shown that the process through which cadmium builds up in the soil, becomes absorbed by rice and comes to affect individual health is a complicated one. But with interdisciplinary analysis, the factors involved can be unpacked and analysed to inform policy responses and public risk communication. In closing we would like to stress a few key points that arise from our analysis.

Reducing pollution sources and levels of cadmium in soil must of course be long term goals to be pursued through the prevention of mining and industry in agricultural areas and enforcement of emissions standards. However, in areas where background levels of heavy metal are high or pollution is already a problem, other measures also need to be taken to ensure food safety. As we have seen, it is not possible to extrapolate from levels of cadmium in soil directly to risks through food. The level of risk will depend upon whether cadmium is bioavailable and whether the crops planted have a propensity to absorb it. It is therefore vital also to understand soil quality and agricultural practices. Where pollution is not too serious, these may also provide options for intervention, for example, through adjusting soil $\mathrm{pH}$ levels, improving organic quality or planting different rice varietals. All of these measures have shown some success in various parts of China (Shi et al., 2009; Yu et al., 2006) and they should be incorporated into agricultural extension services in areas where problems are likely to occur.

Here, the "cadmium rice" problem also interacts both with concerns about food security and product development. In the case of rice, for example, policy has focused on developing and promoting high-yield, Indica-Japonica hybrids ("super rice"), but unfortunately some of these also have a high propensity to absorb cadmium and also have lower uptakes of zinc, which is beneficial to health. Because the choice of crop or cultivar can make the difference between whether food is safe for consumption or not, these interactions need to be considered, especially in areas which may be borderline in terms of levels of soil pollution. In some cases, farmers may have to take losses due to lower productivity, and subsidies may be necessary to provide incentives for change and/or enable a transition to other livelihoods.

Second, in areas where a clear risk is evident at the level of soil and crops, it is important also to consider dietary intake levels and overall nutritional status. Where a population is dependent on local sources of rice that are contaminated, providing an alternative to supplement or replace locally grown rice may be necessary and quicker and more cost effective than attempting remediation of the soil. Some experts have suggested that importing rice from other provinces or countries would be a relatively easy way to rapidly reduce risk in areas that are likely to be problematic. If purchasing power is an issue, subsidies may be necessary to enable poor populations to diversify their food sources.

Third, the health system will need to deal with the impacts of chronic exposure to heavy metals for some time to come, a task for which it is currently not well-equipped. Although China has a comprehensive system for the monitoring of infectious diseases, monitoring of exposure to heavy metals is not a routine task of Chinese Centres for Disease Control and Prevention, which have few resources available for this. While it may be exorbitantly expensive and logistically impossible to test all of China's rice or to provide health testing for the whole population in the short term, it should be possible to identify, through interdisciplinary analysis, places and populations that are likely to be at high risk and to determine needs for priority food and health monitoring, as well as health services.

The processes through which soil pollution generates risks to public health are complex, involving interactions between natural and human systems, and among diverse actors. Effective solutions will require targeted policies from multiple streams, and more effective implementation of existing ones. At the same time, local people are in some cases implicated in the generation of pollution; and they are also able to take some measures to reduce risks to their health even in the absence of responsive policies. A better understanding of the factors that contribute to the generation of risks will enable affected communities and the general public to make more informed decisions for themselves and also to make demands of other actors that will be effective in reducing risk. It is therefore crucial that the findings of research are communicated effectively to both government and the public.

The FORHEAD team has attempted to work on both these levels, through interactions with local government and the preparation and sharing of public education materials in Fenghuang. We hope that in future these can be improved and adapted for use in other contexts. More generally, we hope that the insights from this case study will have broader applicability in helping to understand and address the complex problem of public health risks relating to heavy metals in different local contexts.

\section{Acknowledgment}

This article integrates findings and reflections from an interdisciplinary team of the Forum on Health, Environment and Develop- 
ment FORHEAD, in alphabetical order, Cai Chao, Chen Nengchang, Fang Jing, Jennifer Holdaway, Li Hairong, Li Yonghua, Li Xiaowei, Anna Lora-Wainwright, Lu Jixia, Ran Shenghong, Su Shipeng, Wang Wuyi, Yang Linsheng, Zhang Xiuwu and Zheng Rui. We would also like to recognize the support and input of Teng Shuzhong of the Fenghuang Centre for Disease Control, and to thank Dr Wang and all the other villagers who participated in the Fenghuang project. This work was supported by the Rockefeller Brothers Fund.

\section{References}

Alloway B J and Steinne E, 1999. Anthropogenic Additions of Cadmium to Soils, in McLaughlin M J, and Singh B R eds., Cadmium in soils and plants. Dordrecht: Boston; London: Kluwer Academic Publishers.

Chaney R L, 2012. Food safety issues for mineral and organic fertilizers. Advances in Agronomy, 117: 51-116.

Chaney R L, Reeves P G, Ryan J A. et al., 2004. An improved understanding of soil $\mathrm{Cd}$ risk to humans and low cost methods to phytoextract $\mathrm{Cd}$ from contaminated soils to prevent soil Cd risks. Bimetals, 17: 549-553, 2004.

Chaney R L, Ryan J A, Li Y, et al., 1999. Soil cadmium as a threat to human health. In McLaughlin and Singh eds., Cadmium in Soils and Plants. Kluwer Academic Publishers, Dordrecht. 219-256.

Chen N, Zhang X, Zheng Y, 2018. Heavy Metal Concentrations in Rice from Guangzhou and Associated Health Risks. Journal of Resources and Ecology, 9(1): 85-91.

China Council for International Collaboration on Environment and Development (CCICED), 2010. Developing policies for soil environmental protection in China. Report of the Task Force to the CCICED Annual General Meeting 2010.

http://www.cciced.net/encciced/policyresearch/report/201205/P0201205 29358298439639.pdf

Elinder C G, Kjellström T, Lind B, et al., 1983. Cadmium exposure from smoking cigarettes: variations with time and country where purchased. Environmental Resources. 32(1): 220-227.

FORHEAD, 2014. Food Safety in China: a Mapping of Problems, Governance and Research. FORHEAD report. http://webarchive.ssrc.org/ cehi/PDFs/Food-Safety-in-China-Web.pdf

Grant C A, Bailey L D, McLaughlin M J et al., 1999. Management factors which Influence cadmium concentrations in crops. In McLaughlin and Singh eds., Cadmium in Soils and Plants. Kluwer Academic Publishers, Dordrecht. 151-198.

Grant C A, Clarke JM, Duguid S, et al., 2008. Selection and breeding of plant cultivars to minimize cadmium accumulation. Science of the Total Environment. 390: 301-310.

Inskip H. Beral V, and Mcdowall M, 1982. Mortality of Shipham residents: 40-year follow-up. The Lancet.1 (8277): 896-9.

Ji Y, Li Y, Yang L, et al., 2009. Spatial distribution and ecological significance of heavy metals in typical soil profiles in the Fenghuang lead-zinc mining area, Western Hunan Province. Acta Scientiae Circumstantiae, 29(5): 1094-1102

Kasperson R E, Renn O, Slovic P, et al., 1988. The social amplification of risk: a conceptual framework. Risk Analysis, 8(2): 177-187.

Li X, Lyu B, 2018. The Total Diet Study: Changes in Food Safety Since the First TDS. Journal of Resources and Ecology, 9(1): 28-38..

Li Y, Zhang B, Li H, et al., 2013. Biomarkers of Lead Exposure Among a
Population Under Environmental Stress. Biological Trace Elements Research, 153: 50-57.

Li Y, Zhang B, Yang L, et al., 2013. Blood mercury concentration among residents of a historic mercury mine and possible effects on renal function: a cross sectional study in southwestern China. Environmental Monitoring Assessment, 185: 3049-3055.

Li Y, Zhang X, Yang L, et al., 2012. Levels of Cd, Pb, As, Hg, and $\mathrm{Se}$ in hair of residents living in villages around Fenghuang polymetallic mine, southwestern China. Bulletin of Environmental Contamination and Toxicology, 89(1): 125-128

Li Y, Wang W., Yang, L, et al., 2005. Environmental quality of soil polluted by mercury and lead in polymetallic deposit areas of western Hunan province. Environmental Science, 20(3): 187-191.

Lora Wainwright A, 2017. Resigned Activism: Living with Pollution in Rural China.MIT Press.

Lora-Wainwright A, 2013. Plural forms of evidence and uncertainty in environmental health: a comparison of two Chinese cases. Evidence \& Policy: A Journal of Research, Debate and Practice, 9(1): 49-64.

Lora-Wainwright A, Zhang Y, Wu Y, et al., 2012. Learning to live with pollution: the making of environmental subjects in an industrialized Chinese village. The China Journal, 68: 106-124.

Lu Y, 2016. China's Agricultural Production and Trade in 2016. UK-China Sustainable Agriculture Innovation Network (SAIN) Information Sheet, No.6.

Lu J, Lora Wainwright A, 2014. Historicizing Sustainable Livelihoods: A Pathways Approach to Lead Mining in Rural Central China. World Development. 62: 189-200.

McBride M B, 2002. Cadmium Uptake by Crops Estimated from Soil Total $\mathrm{CD}$ and pH. Soil Science. 167(1): 62-67

Ministry of Land Resources,2015. Report on the Survey of the Earth Chemistry of China's Farmland.

Ministry of Environmental Protection \& Ministry of Land and Resources, 2014. The Public Report of National Situation Regarding Soil Pollution 2014. (in Chinese).

Mohanty S, 2013. Trends in global rice consumption. Rice Today, Jan-Mar (2013): 44-45.

Organisation for Economic Co-operation and Development (OECD), 1994. Risk reduction monograph no. 5: Cadmium: background and national experience with reducing risk. Environment Directorate of OECD, Monograph Series No.104. OECD/GD(94)97.

Pang J, Gong J and Liu H, 2013. Confronting China's cadmium-laced rice crisis: Doing nothing about toxic cadmium in rice paddies appears to be no longer an option in Hunan province. Caixin Online. 5 June. http:// english.caixin.com/2013-06-05/100537850.html

Reeves P G, Chaney R L, 2008. Bioavailability as an issue in risk assessment and management of food cadmium: A review. Science of the Total Environment, 398: 13-19.

Shi J, Li L and Pan G, 2009. Variation of grain Cd and Zn concentrations of 110 hybrid rice cultivars grown in a low-Cd paddy soil. Journal of Environmental Sciences, 21(2): 168-172.

Slovic P, 1987. Perception of risk. Science, 236(4799): 280-285.

Sun H, Li Y, Ji F, et al., 2010. Environmental contamination and health hazard of lead and cadmium around Chatian mercury mining deposit in western Hunan Province, China. Trans Nonferrous Metal Soc China 20: $308-314$. 
Umemura T, 2000. Experimental reproduction if itai-itai disease, a chronic cadmium poisoning of humans, in rats and monkeys. Journal of Japanese Veterinary Resesearch. 48(1): 15-28.

U.S. Department of Health and Human Services. 2012. Toxicological profile for cadmium. Public Health Service. Agency for Toxic Substances and Disease Registry. Available: http://www.atsdr.cdc.gov/toxprofiles/ tp.asp?id=48\&tid=15.

Wang J, Lu D, Chen S, et al., 1994. Investigation on the effect of environment pollution in Fenghuang Lead-zinc mine on human health. Chinese Journal of Public Health, 10(3): 121-122.

World Health Organization, 1992. Environmental Health Criteria 134Cadmium. International Programme on Chemical Safety Monograph, Geneva, Switzerland.

Wu Y, Li X, 2015. The Fourth China Total Diet Study. Chemical Industry Press.

Xie Y, Cao Y, Du X, et al., 2015. Development and validation of a sampling design optimization procedure for detailed soil pollution investigation (in Chinese). Acta Scientiae Circumstantiae, 36(3): 981-989.
Yu H, Wang J, Fang W, et al., 2006. Cadmium accumulation in different rice cultivars and screening for pollution-safe cultivars of rice. Science of The Total Environment, 370 (2-3): 302-309.

Zhai Q, Narbad A, Chen W, 2015. Dietary Strategies for the Treatment of Cadmium and Lead Toxicity. Nutrients, 7(1): 552-571.

Zhang X, 2011. Health risk identification and assessment study for the residents of rural mining village of Fenghuang County [D], Institute of Geographical Sciences and Natural Resources Research, Chinese Academy of Sciences.

Zhang X, Yang L, Li Y, et al., 2012. Impacts of lead/zinc mining and smelting on the environment and human health in China. Environmental Monitoring Assessment. 184(4): 2261-2273.

Zheng R, Rao L, Zheng X, et al., 2015. The more involved in lead-zinc mining risk the less frightened: a psychological typhoon eye perspective. Journal of Environmental Psychology, 44(Dec): 126-134.

Zhou Z, Tian W, Wang J, et al., 2012. Food consumption trends in China. Report submitted to the Australian Government Department of Agriculture, Fisheries and Forestry, April.

\section{从土壤污染到“镉大米”，进而对公众健康的影响——驱动因素和解决方案的跨学科分析}

贺珍怡 ${ }^{1,2}$, 王五一 2

1. 牛津大学跨学科区域学院, 牛津 OX2 6LH, 英国;

2. 中国科学院地理科学与资源研究所, 北京 100101

摘 要: 本文论述了在中国大米镉污染的原因, 并指出了问题的严重性。认为仅仅从土壤中镉的含量简单推断其健康危害 具有误导性, 因为农作物对于镉的吸收以及对于健康的危害受多种因素的影响。不仅包括镉的背景水平以及采矿和工业活动造成 的污染, 而且与土壤性质、气候条件以及农作物的种类密切相关。社会和文化因素, 以及饮食习惯、其它污染源、营养状况和健 康情况也会影响镉的摄入量, 并关系到健康影响的严重程度。基于这些原因, 我们认为跨学科的分析对于更好地了解镉污染对健 康的风险模式以及制定有效干预措施至关重要。

关键词: 土壤污染; 食品安全; 镉; 大米; 环境健康; 中国 